\title{
Optimization of Land Saving and Loss Reducing and Slope Stability Variation Patterns in Open-Pit Mine
}

\author{
Tongsuo Guo, ${ }^{1,2}$ Wei Zhou $\mathbb{D}^{1,2}$ Zhaolin Li ${ }^{10},{ }^{1,2}$ Chuanwei Zhang, ${ }^{1,2}$ Qingxiang Cai, ${ }^{1,2}$ \\ Ya Tian, ${ }^{1,2}$ Huairui Qin, ${ }^{1,2}$ Fuming Liu, ${ }^{1,2,3}$ Izhar Mithal Jiskani $\mathbb{D}^{1,2}$ and Dongxu Zhang ${ }^{4}$ \\ ${ }^{1}$ High-Tech Research Center for Open Pit Mines, China University of Mining and Technology, Xuzhou, Jiangsu 221116, China \\ ${ }^{2}$ State Key Laboratory of Coal Resources and Safe Mining, China University of Mining and Technology, Xuzhou, \\ Jiangsu 221116, China \\ ${ }^{3}$ Xinjiang Tianchi Energy Sources Co., Ltd, Changji 831100, China \\ ${ }^{4}$ China Coal Technology Engineering Group Shenyang Research Institute, Fushun, 113122 Liaoning, China
}

Correspondence should be addressed to Wei Zhou; loutian1982@126.com

Received 11 December 2020; Revised 20 February 2021; Accepted 29 March 2021; Published 15 April 2021

Academic Editor: Feng Xiong

Copyright (c) 2021 Tongsuo Guo et al. This is an open access article distributed under the Creative Commons Attribution License, which permits unrestricted use, distribution, and reproduction in any medium, provided the original work is properly cited.

\begin{abstract}
This study presents different land saving and loss reducing schemes. Comprehensively compare the economic benefits of the schemes. It is shown that the optimal scheme can recover tons of coal resources on the south slope, creating significant economic benefits. Numerical simulation was utilized to analyze the changes of slope stability, deformation, and shear strain increment in the process of land saving and loss reducing. Results found that the slope stability decreases rapidly, and the toe of the slope has to be internally discharged in time to compress the slope. Timely follow-up of in-slope rows can improve slope stability. The position of the slope shear exit changes with the increase of the distance of the inner row, and its stability increases gradually. When the distance of the lower inner row exceeds $120 \mathrm{~m}$, the increase of the internal row distance has little influence on the slope stability. When the inner distance exceeds $60 \mathrm{~m}$ in the process of internal dumping of upper platform, the position of potential sliding plane gradually changes from the lower dump to the upper and lower dump with the increase of inner dumping distance. It shows that the stability of the dump will be damaged if the upper dump continues to be discharged. Therefore, the distance between the upper and lower dump sites is more important than $60 \mathrm{~m}$. The stability of the south slope is good in the process of mining and internal drainage, and the overall stability of the south slope is controllable, based on slope radar monitoring.
\end{abstract}

\section{Introduction}

As China's main source of energy, coal ranks first in the energy structure in terms of both extraction and consumption [1]. By virtue of the advantages of fast construction, low production costs, and high resource extraction rates, open-pit mining has achieved rapid development in recent years [2], and the technology of open-pit mining has been constantly improved, with the proportion of production exceeding $20 \%$ and the output of a single open-pit mine reaching tens of millions of tons per year. However, the large-scale mining operations caused by the waste of coal resources is also more prominent, according to statistics China's annual loss of coal resources in the billion tons, resulting in a huge waste of resources and economic losses.

In addition, large open-pit mines in China are mainly located in remote areas such as Xinjiang and Inner Mongolia, where the ecological environment consists mostly of fragile Gobi or grasslands [3], and the open-pit mining operations [4] have caused large-scale damage to the geological structure and vegetation in these areas $[5,6]$. In the past 10 years, the large-scale development and construction of open-pit coal mines has caused the destruction of surface vegetation [7], exacerbated desertification in mining areas, and accelerated the degradation of local ecosystems $[8,9]$. Innovative strategies have been developed to mitigate the impact of mining, which is of great significance to the sustainable development 
of the mining industry [10-13]. Among various methods proposed, how to improve the mining process of raw coal under the existing production conditions to reduce the damage of open-pit mining to the environment and land resources, as well as to increase the recovery rate of coal resources during the mining process is of great importance to open-pit mines $[14,15]$.

To address the operation characteristics of large-scale stripping and dumping in open-pit mining [16, 17], the development of land saving and loss reducing mining technology for open-pit mines based on temporal slope theory can effectively solve the problems of coal loss [18], land and environmental damage in the open-pit mining process, reduce the impact on the ecology of the mine, and have good economic and environmental benefits [19]. In the initial stage, the land saving technology was mainly applied to the improvement of the production capacity and zoning process of open-pit coal mines in China, which is easier to build soil discharge field in the mine due to the characteristics of the coal seam. During the mining process, the inner dump follows up with the advance of the working slope $[20,21]$. The end slope located on both sides of the open-pit mine was changed from long-term exposure to short-term exposure and then buried [22]; as a result, the static and permanent end slope has timeliness. However, in the past, the design of end slope angle is always based on the static angle [23], which is overly conservative at this time, resulting in serious coal pressure in the lower part of the pit and causing a lot of waste of resources [24].

The technology of land saving and loss reducing attaches great importance to the reduction of ecological damage on the surface of the earth, which involves expanding the boundary of the bottom of the mine without changing the surface boundary, compressing the flat plate width of the lower coal steps of the end slope to improve the slope angle, and changing the straight slope to an upward and downward steep slope to improve the recovery rate of the lower coal resources and achieve resource reduction [25]. However, this technology also brings some problems: due to the steepening of the end slope, the width of flat plate and overlying rock seam is reduced, which sacrifices the development of the transportation system and greatly increases the distance and freight cost of the inner row of materials and also affects the stability of the slope $[26,27]$. Therefore, in the process of land saving and loss reduction, the proportional structure optimization needs to take into account both engineering safety and resource recovery, which greatly increases the construction difficulty [28].

In view of this, this study will present different land saving and loss reducing schemes by taking Xinjiang south open-pit mine as an example, comprehensively compare the economic benefits of the schemes, propose reasonable mining schemes. The numerical calculation model will be established to analyze the slope stability variation law in the process of land saving and loss reduction mining and inner drainage. It provides important technical reference and has significant engineering significance for improving the safety of the project site and realizing the integration of land saving and loss reduction and mining technology.

\section{Geological Overview of South Open-Pit Mine Engineering}

The south open-pit mine is located in the western part of Dajing coalfield in the Zhundong coalfield of Xinjiang, on the eastern flank of the dorsal slope of the Tepenggou at the southern foot of the Krameri Mountains, with a general trend of gently sloping terrain in the north and the south, and the geomorphological pattern is that of a residual mound-like stripped plain. The stratigraphy is monoclinic in a northeast-east direction and southeast-south inclination, with dips ranging from $4^{\circ}$ to $15^{\circ}$, and the overall surface of the mine is a simple monoclinic structure that dips gently, with little change in orientation or inclination. The average thickness of the coal seam is $76 \mathrm{~m}$, which is a giant thick coal seam. The side slopes of the South open-pit mine are composed mostly of soft rocks and are significantly influenced by environmental factors such as weathering and disintegration. There is no perennial surface water flow or spring water exposure in the mine, and temporary surface water flow is formed in the valley during the snowmelt season and after heavy rainfall in summer.

The mine stratum is roughly divided into three parts, in which the upper part is mainly composed of gray and grayish-brown fine debris deposits, and is mainly characterized by several layers of grayish-white, gray, earthy-yellow, and other tones of mudstone of 3-5 m thickness; the coarsegrained fine sandstone (local siltstone) is mostly gray; the fine siltstone and muddy siltstone are mostly grayish-brown, and the mudstone is mostly bright miscellaneous color; the bottom of which has turned gray, and the mudstone at the top of the coal seam is grayish-black. The coal seam in the middle part is a huge thick coal seam, containing $0 \sim 1$ layers of gangue, and the gangue lithology is mainly mudstone and high carbon mudstone, with local mudstone and siltstone, and the top and bottom plates are mainly mudstone. The base layer of the coal seam is mainly composed of gray mudstone and gray-white medium-fine sandstone, while the local phase changes into conglomerate sandstone, powder, and fine sandstone, which has the geological characteristics of gray-white, quartz as the main component, coarse grain size and stable extension, interspersed with mudstone, carbonaceous mudstone, carbonaceous mudstone and coal line, and the texture of the mudstone can be seen in the mudstone.

\section{Schemes for Land Saving and Loss Reducing in South Open-Pit Mine}

The South open-pit mine has entered the internal drainage period since 2018, the east slope beganed a working slope as shown in Figure 1, while the south slope gradually formed an end slope.. The basic operating procedure of open-pit mining is to advance the working slope continuously at a certain speed. The coal seam is first stripped of the supporting rock layer (soil and rock body), and then, the coal seam is extracted and pushed forward until there is enough space in the mining field, and then, the stripped coal is transported to the nonworking slope for backfilling. In this process, the inner discharge field and the working slope are dynamically 


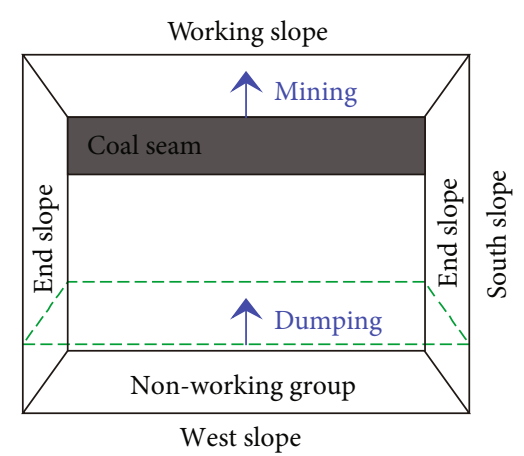

FIGURE 1: Sketch map for stope advance schematic.

tracked. However, processes such as cover stripping and ore body mining break the integrity of the strata and also cause ecological damage. In recent years, with the continuous implementation of the concept of green development, the promotion of green coal mining has become a major demand for the high-quality development of the coal industry in the new era. Therefore, the open-pit mining process should aim at minimizing ecological damage to the environment and maximizing the conservation and utilization of land resources, thus significantly reducing the duration and scope of disturbance to the ecosystem.

Therefore, based on the theory of steep end-slope mining technology developed by the time-dependent slope theory, this study puts forward the scheme of land saving and loss reducing, which integrates the green mining concept of "reducing the loss of coal resources" and "saving land" in order to achieve a win-win situation for both the economic benefits of the mine and the land environment in the mining area. As shown in Figure 2, traditional methods of recovering coal resources tend to adopt a constant slope angle, with the foot of the slope advancing from point $E$ to point $D$ (blue dashed line in Figure 2), yet result in a significant loss of surface $\mathrm{AA}^{\prime}$ land resources.

Therefore, this study proposes the following land saving and loss reducing scheme: maintaining the surface point $A$ fixed and advancing the foot of the slope from point $E$ to point $D$ on the precondition that the slope is stable during the service period, which can realize the low-cost recovery of coal resources in the BCED region and only requires the stripping of rock masses in the $\mathrm{ABC}$ region. The stripping ratio of this stage is much smaller compared to the average stripping ratio of the mine, which has significant economic and environmental benefits and greatly reduces the damage to land resources. Therefore, the key technology in this study is that during the construction of land saving and loss reduction, as the slope angle becomes larger (from $\beta$ to $\alpha$ ), the probability of slope failure and the difficulty of mining increase accordingly, which may cause safety accidents due to slope instability. However, considering that the inner-dumping with burying slope can reenhance the stability of the slope in the later stage, this study will monitor and systematically propose the recovery of coal resources under the

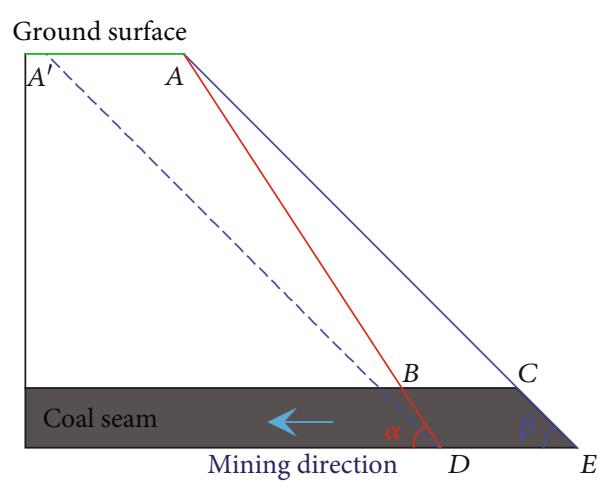

FIgURE 2: Mining plan with land saving and ecological detraction.

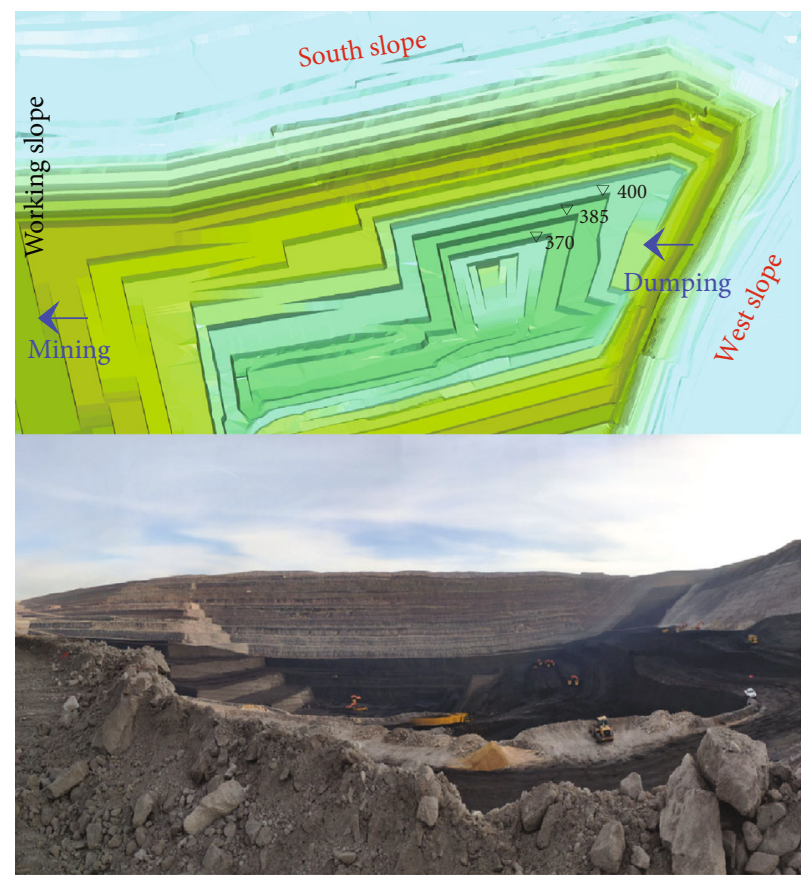

FIgURE 3: Overview and schematic diagram of the south slope site.

short-term stable state of the slope according to the multiple means in the field and fully study the maximum recovery effect of the slope stability and coal resources.

According to the geological conditions of the south slope (Figure 3), land resources, and the internal drainage of the west slope, the overlying rock platforms are not changed in the whole land saving and loss reducing scheme, and the coal bench width is reduced. At present, there are five coal platforms in the south slope, which are 400, 385, 370, 355, and 340 . According to the preliminary design, $30 \mathrm{~m}$ is reserved for the 400 level as the transport level, $10 \mathrm{~m}$ for the 383 level as the security flat plate, $30 \mathrm{~m}$ for the 370 level as the transport level, and $10 \mathrm{~m}$ for the 355 level as the security flat plate.

At present, the internal drainage platforms of 370, 400, and 430 levels have been established west slope. The amount of stripping that can be accommodated by the 370 horizontal inner row platform of the south slope is small. Moreover, since the stripping materials of the working slope (east slope) 


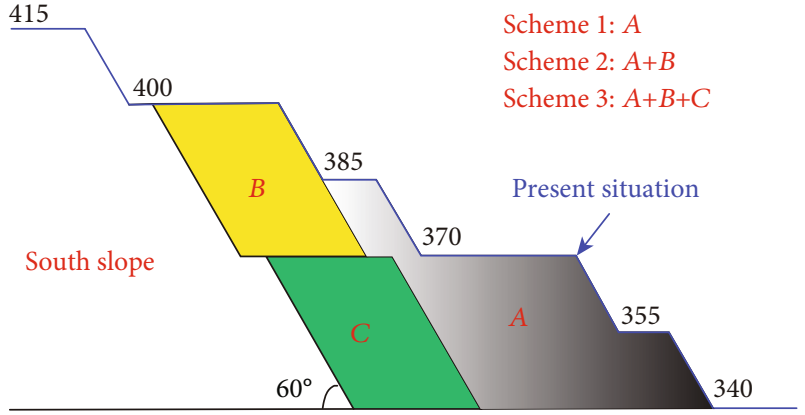

FIGURE 4: Land saving and loss reducing schemes for south slope.

TABLE 1: Corresponding table for internal discharge of stripping materials on working slope.

\begin{tabular}{lccc}
\hline & \multicolumn{3}{c}{$\begin{array}{c}\text { Internal drainage level } \\
\text { (west slope) } / \mathrm{m}^{3}\end{array}$} \\
\hline Stripping level (east slope) & 370 & 400 & Total \\
\hline $400-415$ & 75 & - & 75 \\
$415-430$ & 140 & 24 & 164 \\
$430-445$ & - & 164 & 164 \\
$445-460$ & - & 258 & 258 \\
Total & 215 & 446 & 661 \\
\hline
\end{tabular}

are mainly distributed above the 400 level platform, which need to be transported downward when constructing the internal dump, leading to unrealize the same level transportation. Therefore, it is not necessary to set up the 370 horizontal transport channel in south slope. The stripping steps of the working slope are above 400 level, which is connected with the inner discharge platform of the west slope, forming a double ring transportation channel for the inner discharging materials. Considering that the coal platform on the south slope is provided with transportation channel and comparing the economy of different layout schemes, the bench layout and mining scheme of the south slope are determined, as shown in Figure 4.

3.1. Scheme 1. Scheme 1 is to mine the coal resources in area A (Figure 4). After the establishment of the inner discharge platform on the western slope, the 400 level on the southern slope is left as a transport channel. The advantage is that the materials on the east slope (work slope) can be discharged to the 400 level inner row platform on the west slope through double-loop transportation (south and north route). It greatly shortens the internal transportation distance and reduces the transportation cost. However, the disadvantage is obvious: the 30-meter transportation channel left on the end slope causes a large amount of coal resources to be overburdened. Since the South open-pit mine is a huge thick coal seam, the 400 level is the uppermost coal platform, and the amount of coal resources under pressure is even larger.

Table 1 shows the corresponding relationship between stripping material and internal drainage of work slope. The stripping materials of work slope (east slope) are mainly concentrated above 400 level, and all stripping materials below

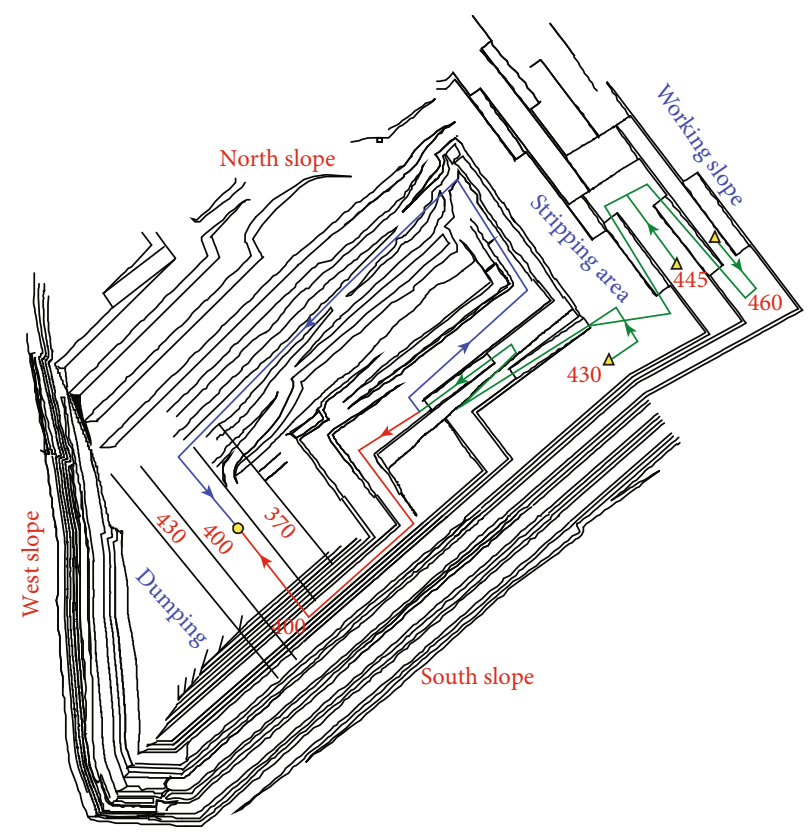

FIGURE 5: Material transportation diagram for the corresponding work slope on the west slope in-row platform.

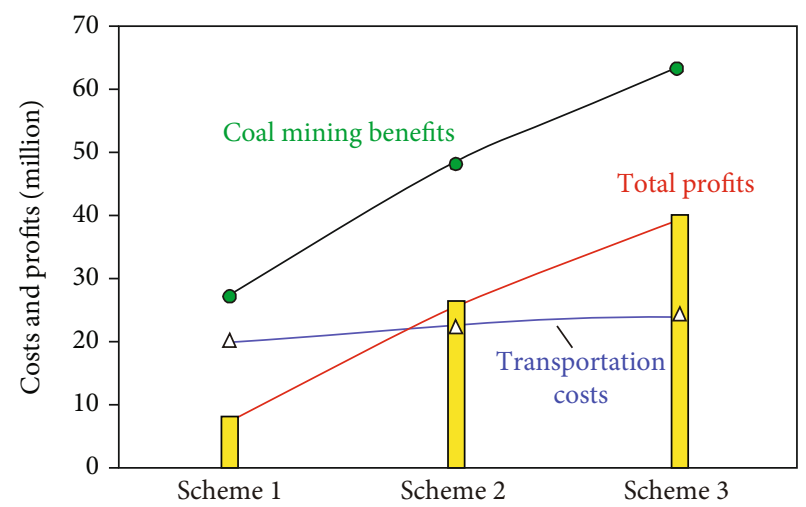

FIgURE 6: Comparison of the economic benefits of different options.

550 level are discharged inside according to the site. There are $370,400,430,460$, and other levels on the inner terrace of the west slope.

Figure 5 shows the material transportation routes for the west slope corresponding to the inner drainage platform from the working slope (eastern slope). The stripping material of the 400 level inner drainage platform on the west slope comes from the east slope at the 430, 445, and 460 levels (Table 1). According to Figure 5, the transportation distance of working slope 430, 445, and 460 stripping platform along the north south slope is measured, respectively.

The transportation cost is calculated according to the measured transportation distance:

$$
Q=V \times\left(\sum_{i=1}^{n} L i \times a+\sum_{j=1}^{n} H j \times b\right),
$$




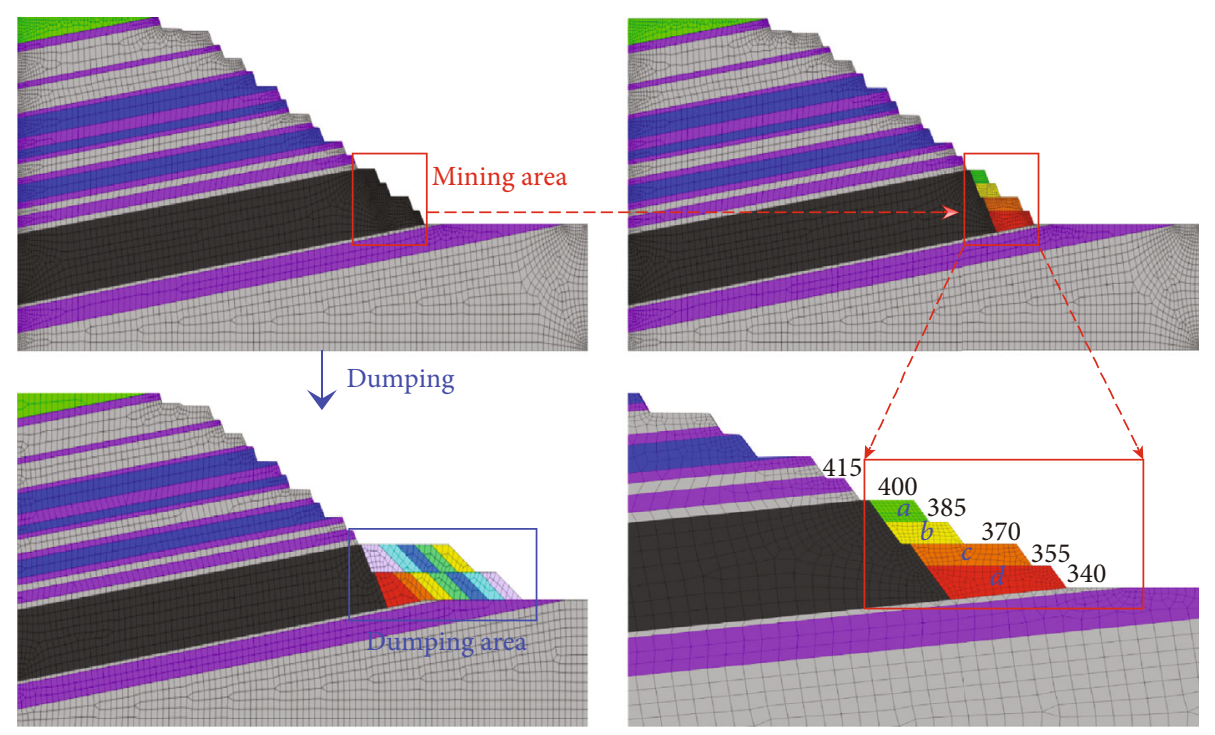

FIGURE 7: Numerical calculation model of south slope mining and inner drainage.

Table 2: Physical and mechanical parameters of rock and soil.

\begin{tabular}{lccc}
\hline Stratum & $\begin{array}{c}\text { Density } \rho \\
\left(\mathrm{g} / \mathrm{cm}^{3}\right)\end{array}$ & $\begin{array}{c}\text { Cohesion } C \\
(\mathrm{KPa})\end{array}$ & $\begin{array}{c}\text { Internal friction } \\
\text { angle } \varphi\left({ }^{\circ}\right)\end{array}$ \\
\hline Dumping material & $1.98-2.21$ & $13.2-17.8$ & $23.5-26.1$ \\
Quaternary & $1.911-2.103$ & $33.4-36.5$ & $13.8-15.1$ \\
Mudstone 1 & $2.147-2.233$ & $286-313$ & $14.7-16.5$ \\
Mudstone 2 & $2.144-2.215$ & $310-341$ & $15.8-17.3$ \\
Mudstone 3 & $2.493-2.579$ & $317-350$ & $16.1-18.2$ \\
Siltstone 1 & $2.018-2.135$ & $314-346$ & $16-19.6$ \\
Siltstone 2 & $2.031-2.146$ & $342-377$ & $17.1-20.2$ \\
Fine sandstone & $2.246-2.367$ & $368-398$ & $19.3-22.3$ \\
Coal & $1.248-1.322$ & $240-372$ & $16.6-19.8$ \\
\hline
\end{tabular}

where $Q$ is the total transportation costs, yuan; $V$ is the volume of transported materials, $\mathrm{m}^{3} ; L i$ is the horizontal transportation distance of materials on the $i$-th platform, $\mathrm{km} ; \mathrm{Hj}$ is the lifting height of material on the $j$-th platform, $\mathrm{m} ; a$ is the unit price of materials in horizontal transportation, yuan $/ \mathrm{m}^{3} \cdot \mathrm{km} ; b$ is the unit price of materials lifting transportation, yuan $/ \mathrm{m}^{3} \cdot \mathrm{m}$; and $n$ is the number of stripping platforms.

3.2. Scheme 2. Scheme 2 is to mine the coal resources in areas $A$ and $B$ (Figure 4). The 400 horizontal transport channel is cancelled, leaving only the 370 horizontal transport channel. It has the advantage of double ring transportation of materials at the bottom of internal discharge. It has the advantage of double ring transportation of materials at the bottom of internal discharge. The materials close to the south slope can be discharged through the south slope, which shortens the internal discharge distance of some stripped materials and reduces the freight. However, the shortcomings caused some of the coal resources on the south slope to be overwhelmed.

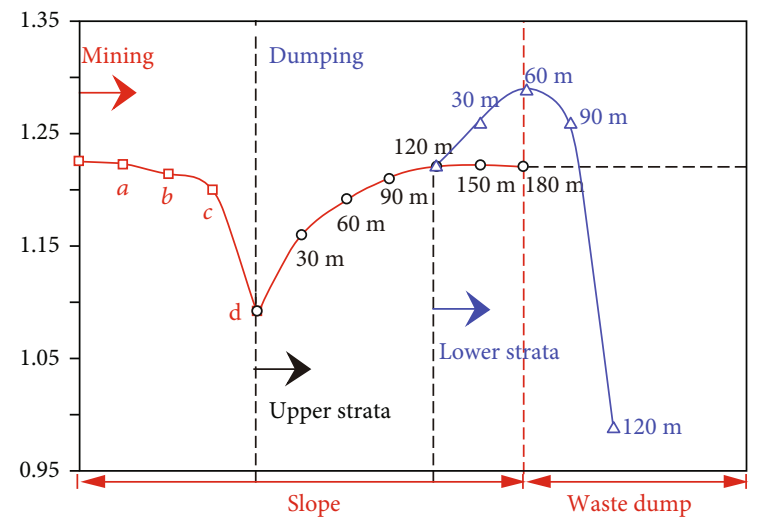

Figure 8: Variation law of slope stability in the process of land saving and loss reducing.

3.3. Scheme 3. In the scheme design, 370 and 400 horizontal transport channels are not reserved on the south slope. Since there is no transport channel left in the south slope coal bench, 370 and 400 inner row horizontal stripping material can only be transported through the north slope, thus increasing the transport distance. However, the recovery of coal resources on the south slope has been greatly increased.

Considering the average price and comprehensive cost of coal, the profit per ton of coal is 34.67 yuan/t. In scheme 1, the south slope can recover about 0.8 million tons of coal resources and make a profit of 27.736 million yuan. 400 horizontal double-ring transport is used, with freight costs of approximately 20.05 million yuan, representing a total profit of 7.686 million yuan. The scheme 2 can recover about 1.4 million tons of coal resources and make a profit of 48.538 million yuan. Using 370 horizontal double ring transportation, the freight is about 22.71 million yuan, representing a total profit of 25.828 million yuan. The scheme 3 can recover about 1.84 million tons of coal resources and make a profit of 63.792 million yuan. Adopting single-ring transportation 


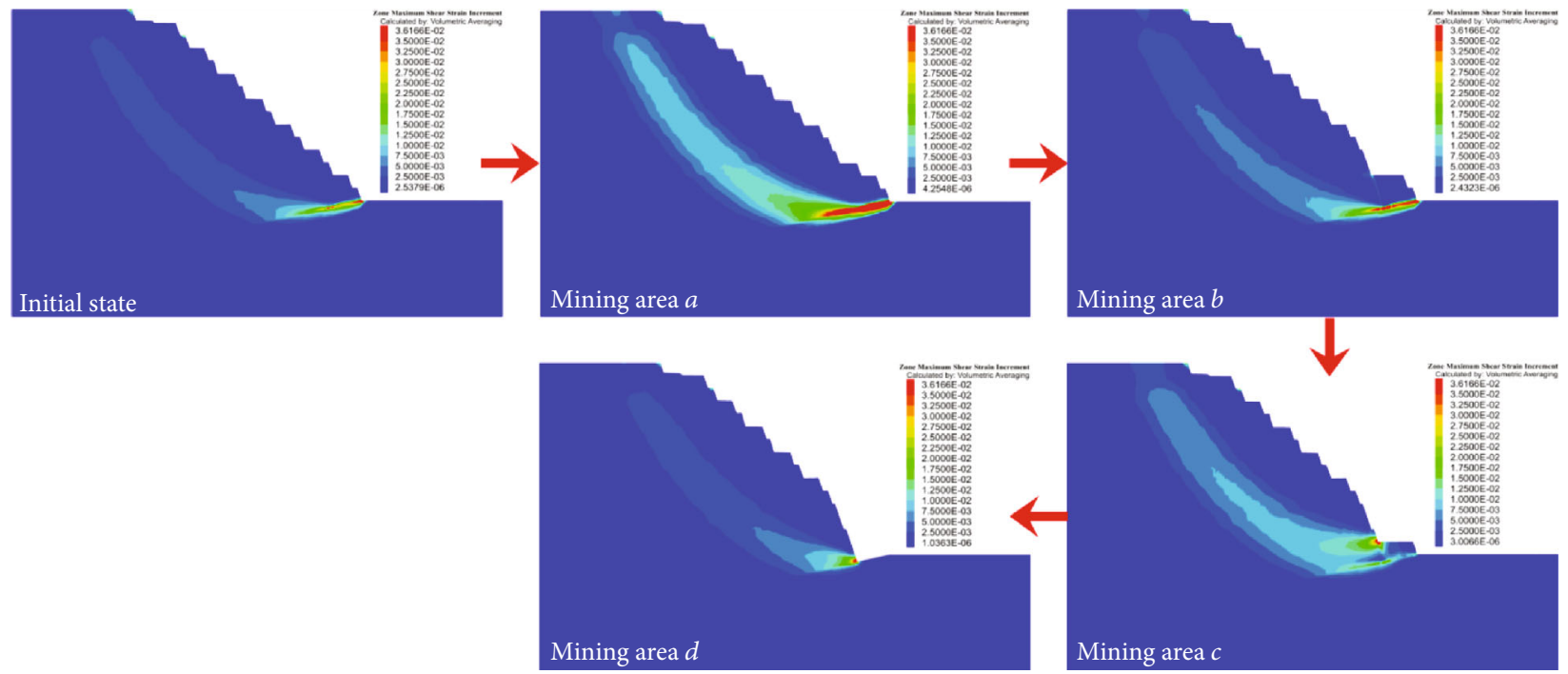

FIGURE 9: Variation law of shear strain increment during mining process of south slope.

(inner row of materials on the north slope), the freight cost is about 24.43 million yuan, and the total profit is 39.362 million yuan (Figure 6).

The scheme 3 can maximize the recovery of coal resources in the south slope, generate the largest profit. This scheme will be used given the significant effect of land saving and loss reduction. In addition, the stability of the southern slope due to the elimination of the transport platform requires in-depth analysis. Therefore, the following section will focus on the dynamic law of slope stability in the process of land saving and loss reduction.

\section{Evolution of Slope Stability in the Process of Land Saving and Loss Reducing}

According to the geological profile of the site, a numerical calculation model of mining and internal drainage in the slope saving and degradation project is established as shown in Figure 7. The mining process is roughly divided into four stages. The four coal platforms in Figure 7, $a$ (385-400 level), $b$ (370-385 level), $c$ (355-370 level), and $d$ (340-355 level), are mined in sequence. Afterwards, an inner row was conducted on the exposed slope to strengthen the stability of the slope. The physical and mechanical parameters of the south slope were adopted as Table 2, and the numerical calculations were based on the strength reduction method to analyze the change law of slope stability.

Figure 8 shows the variation law of slope stability in the process of land saving and loss reduction. Figure 9 presents the variation law of shear strain increment of South Central slope during coal mining. The potential sliding plane of the slope is approximately arc-shaped. As the mining coal seam advances downward, the front edge of the sliding body shows an obvious translational trend along the coal floor. The potential for sliding gradually changes to a rotationplanning failure mode. A large change in the potential slip trend occurred in the process of mining area $c$ to area $d$. It indicates that the inner drainage should be carried out in time after the coal seam is mined (the slope stability coefficient in Figure 8 decreases obviously).

A similar rule can also be obtained from Figure 10: the location of shear exit on the south slope has not changed during the mining of areas $a$ to $b$ (always along the coal floor). After mining area $c$, the steps on the south slope have become steeper, and the 370 platform has a large advancing distance (advancing $60 \mathrm{~m}$ ). The slope foot is changed from the original 355 platform to the 370 platform. At this time, the $355 \sim 370$ steps function as the presser foot to move the cutting outlet upward. After the mining area $d$, the foot of the slope is unrestrained, and the slick surface is sheared out from the coal floor again. Due to the overall steepening of the slope, the foot of the slope needs to be drained inside the slope in time, and the slope stability factor decreases considerably at this time (the slope stability coefficient in Figure 8 decreases obviously).

Timely follow-up of in-slope rows can improve slope stability, and the horizontal row field below 400 is divided into two platforms. Figure 11 shows the variation law of slope shear strain increment under different inner row distance. When the inner row distance is $60 \mathrm{~m}$, the potential slip plane crosses the entire south slope as well as the inner row soil field. It shows that the distance of internal dumping is low, and the slope stability does not reach a constant state (Figure 8). When the inner row distance is $120 \mathrm{~m}$, the slope shear outlet position roughly falls in the coal seam slope foot position; the inner row soil field slope foot also appears shear sliding surface. It shows that the internal dump can improve the slope stability. When the inner row distance is $180 \mathrm{~m}$, there is no shear sliding plane at the toe of the inner dump. It shows that increasing the inner row distance has little effect on slope stability at this time (the slope stability coefficient is basically unchanged in Figure 8). Therefore, the lower level of the discharge field is set at $120 \mathrm{~m}$.

In the process of the upper platform inner row, when the inner row distance is $30 \mathrm{~m}$, there are shear outlets on the upper and lower inner row platforms, which indicates that 


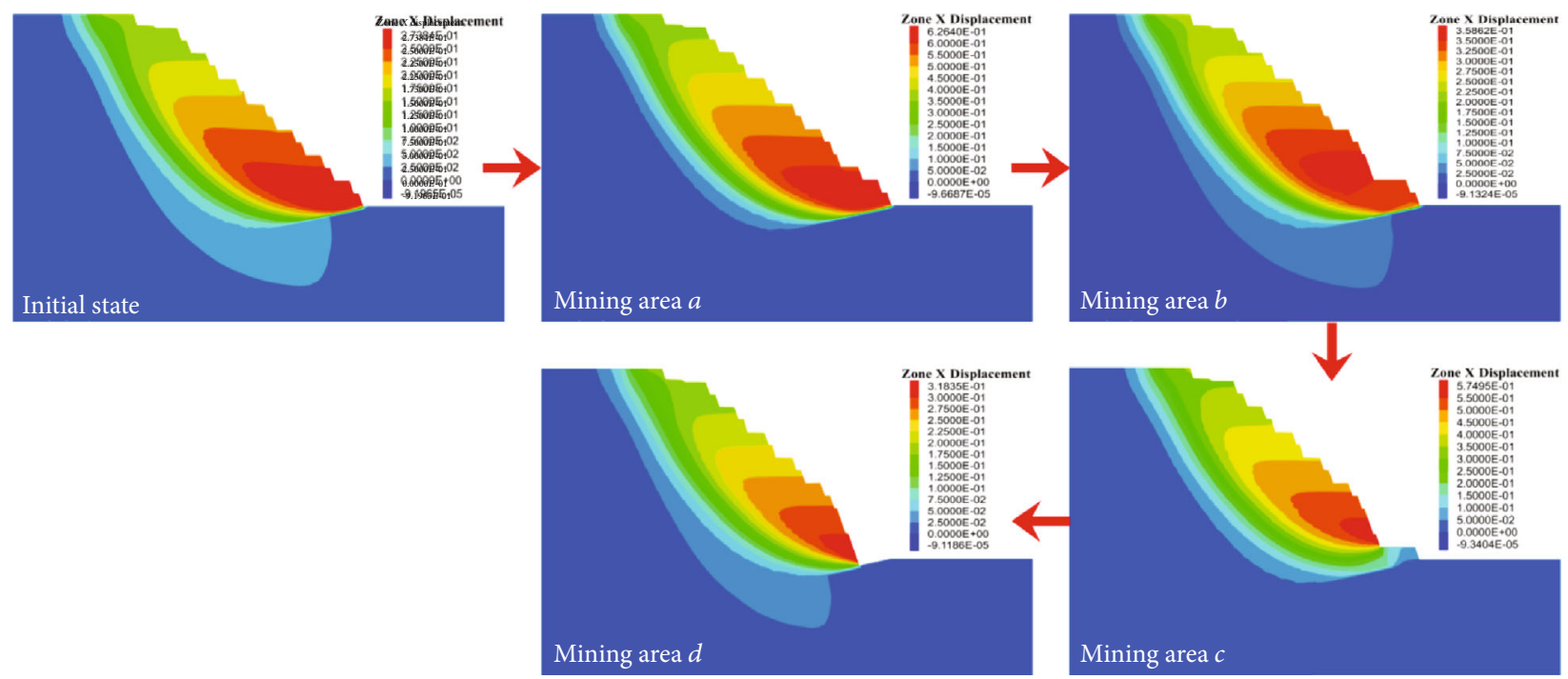

Figure 10: Variation law of horizontal displacement ( $x$ direction) in south slope mining process.

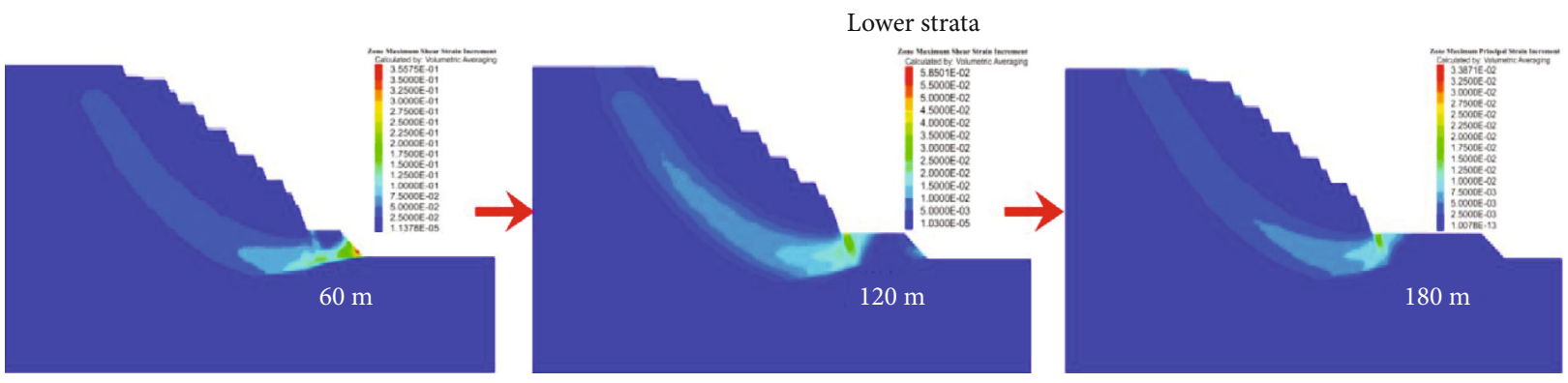

(a) Lower strata

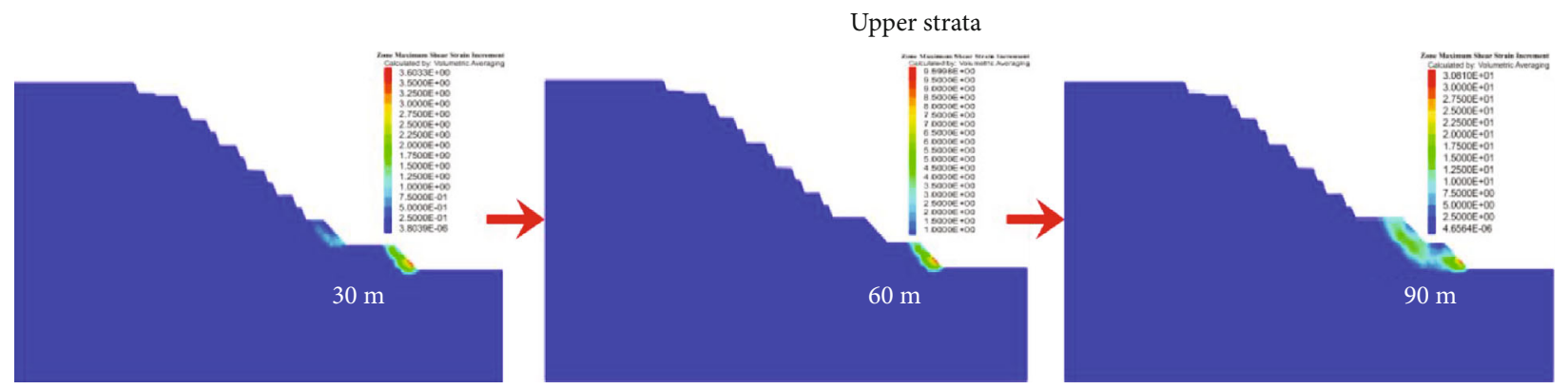

(b) Upper strata

FIGURE 11: Variation law of slope shear strain increment under different inner row distance.

the stability of the upper platform is relatively low at this time, and further inner drainage is needed. When the distance of the inner row is $60 \mathrm{~m}$, only the shear outlet appears in lower inner row platforms, which indicates that the slope stability has been improved. When the inner row distance is $90 \mathrm{~m}$, the entire upper and lower inner row steps form a larger shear sliding surface, indicating that the continuous inner row of the upper steps will damage the stability of the dump (the stability coefficient of the dump decreases sharply in Figure 8). Therefore, the distance between the upper and lower dumps is greater than $60 \mathrm{~m}(120 \mathrm{~m}-60 \mathrm{~m})$.

\section{Slope Stability Observation}

In order to ensure the stability of the slope in the process of land saving and loss reduction, slope radar was used to monitor the displacement of the south slope. By analyzing the displacement and displacement rate of the slope, it was predicted whether the slope was at risk of landslide in a short time. A total of four monitoring areas were set up at the site, as shown in Figure 12.

According to the geological condition of the slope (Figure 13), the steep slope was mined from January to 


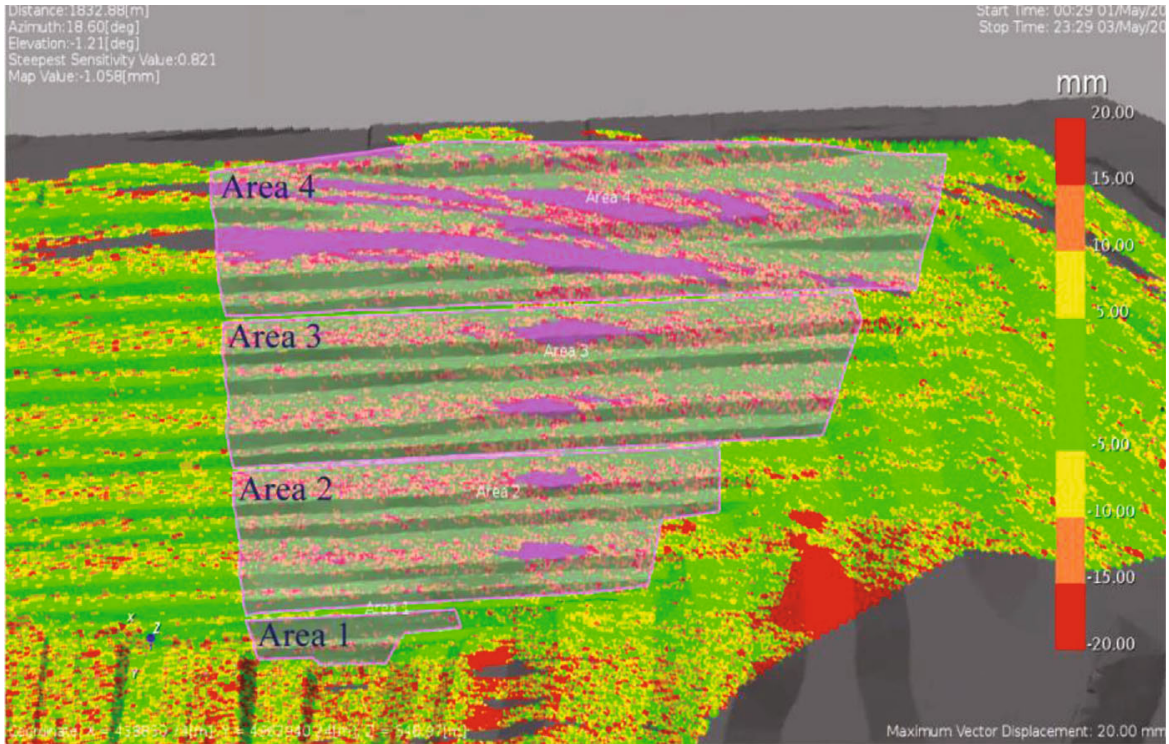

FIgURE 12: Area of radar monitoring on the south slope.

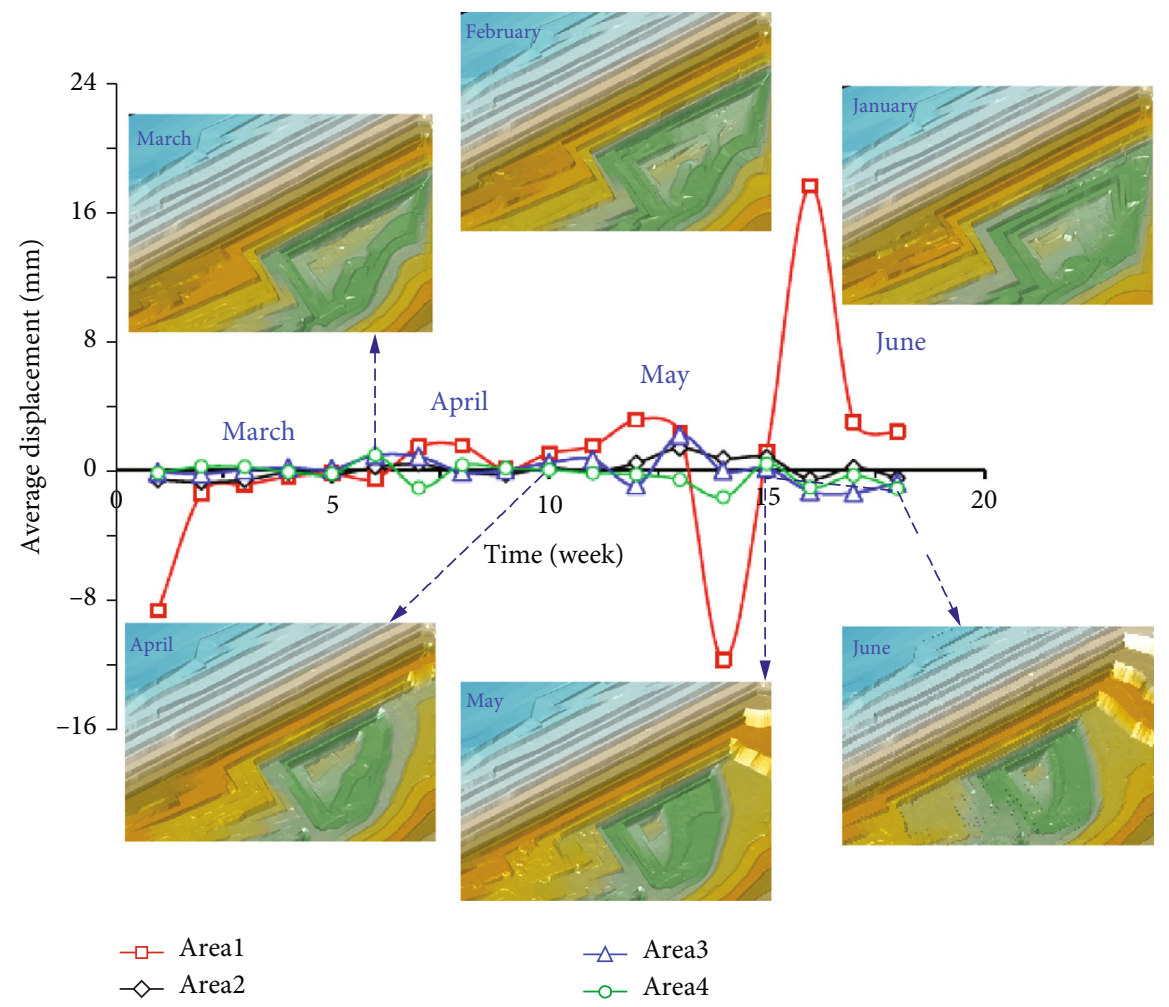

FIGURE 13: Deformation variation law of south slope monitored by radar.

February, and the coal seam shown in scheme 3 was extracted in sequence (Figure 4), followed by the inward discharge in March, which was advanced from the west slope to the east. The average deformation of the south slope was always below $20 \mathrm{~mm}$ and remained below $5 \mathrm{~mm}$ from March to May. Occasional local rock fall occurs on the slope but does not affect the overall stability of the slope, and the overall steps are stable. Affected by the construction of excavators, except for local monitoring data is high (May to June), the overall safety range is within the overall stability of the south slope can be controlled.

\section{Conclusion}

(1) The technical schemes of land saving and loss reducing in different open-pit mining are put forward. By comparing the economic benefits and engineering transportation costs and other factors, it is found that 
the optimal scheme can recover 1.84 million tons of coal resources on the south slope, creating significant economic benefits

(2) Numerical simulation was utilized to analyze the changes of slope stability, deformation, and shear strain increment in the process of land saving and loss reducing. In the process of coal seam excavation, the slope stability decreases rapidly, and the potential slip plane changes to rotation-planning damage mode. The overall slope becomes steeper after the coal seam is mined, and the toe of the slope needs to be internally discharged in time to compress the slope

(3) Timely follow-up of in-slope rows can improve slope stability. The position of the slope shear exit changes with the increase of the distance of the inner row, and its stability increases gradually. When the distance of the lower inner row exceeds $120 \mathrm{~m}$, there is no shear sliding plane at the toe of the internal dump, which indicates that the increase of the internal row distance has little influence on the slope stability, and the distance at the lower layer of the dump is $120 \mathrm{~m}$. In the process of internal dumping of upper platform, when the inner distance exceeds $60 \mathrm{~m}$, the position of potential sliding plane gradually changes from the lower dump to the upper and lower dump with the increase of inner dumping distance. It shows that the stability of the dump will be damaged if the upper dump continues to be discharged. Therefore, the distance between the upper and lower dump sites is greater than $60 \mathrm{~m}$

(4) The displacement of south slope is monitored by slope radar. The stability of the south slope is accomplished in the process of mining and internal drainage, and the overall stability of the south slope is controllable

\section{Data Availability}

The data used to support the study can be obtained from the authors.

\section{Conflicts of Interest}

The authors declare that there are no conflicts of interest regarding the publication of this paper.

\section{Acknowledgments}

We gratefully acknowledge the support provided by the China Postdoctoral Science Foundation funded project (Grant No. 2020M671649).

\section{References}

[1] P. Liu, W. Zhou, Q. Cai, X. Shi, and G. Xu, "The thin coal seam (TCS) mining technology for open pit mines in China," Geo- technical and Geological Engineering, vol. 36, no. 6, pp. 3627$3637,2018$.

[2] G. G. Sakantsev, M. G. Sakantsev, V. I. Cheskidov, and V. K. Norri, "Improvement of deep-level mining systems based on optimization of accessing and open pit mine parameters," Journal of Mining Science, vol. 50, no. 4, pp. 714-718, 2014.

[3] W. Cheng, S. Lei, Z. Bian, Y. Zhao, Y. Li, and Y. Gan, "Geographic distribution of heavy metals and identification of their sources in soils near large, open-pit coal mines using positive matrix factorization," Journal of Hazardous Materials, vol. 387, article 121666, 2020.

[4] M. Liu, J. Liu, M. Zhen et al., "A comprehensive evaluation method of bench blast performance in open-pit mine," Applied Sciences, vol. 10, no. 16, p. 5398, 2020.

[5] S. Wang, J. Huang, H. Yu, and C. Ji, "Recognition of landscape key areas in a coal mine area of a semi-arid steppe in China: a case study of Yimin open-pit coal mine," Sustainability, vol. 12, no. 6, p. 2239, 2020.

[6] H. Rahmi, D. Susetyo, and R. Juniah, "Utilization study of void mine for sustainable environment of the limestone mining sector at PT Semen Baturaja (Persero) Tbk," Indonesian Journal of Environmental Management and Sustainability, vol. 3, no. 2, pp. 54-59, 2019.

[7] Z. Li, S. Yu, W. Zhu et al., "Dynamic loading induced by the instability of voussoir beam structure during mining below the slope," International Journal of Rock Mechanics and Mining Sciences, vol. 132, article 104343, 2020.

[8] Y. Bi, Y. Zhang, and H. Zou, "Plant growth and their root development after inoculation of arbuscular mycorrhizal fungi in coal mine subsided areas," International Journal of Coal Science \& Technology, vol. 5, no. 1, pp. 47-53, 2018.

[9] L. Quansheng, "Progress of ecological restoration and comprehensive remediation technology in large-scale coal-fired power base in the eastern grassland area of China," Journal of China Coal Society, vol. 44, pp. 3625-3635, 2019.

[10] C. Qi and A. Fourie, "Cemented paste backfill for mineral tailings management: review and future perspectives," Minerals Engineering, vol. 144, article 106025, 2019.

[11] C. C. Qi, "Big data management in the mining industry," International Journal of Minerals Metallurgy and Materials, vol. 27, no. 2, pp. 131-139, 2020.

[12] A. Zhao, A. Fourie, and C.-c. Qi, "Mechanics and safety issues in tailing-based backfill: a review," International Journal of Minerals, Metallurgy, and Materials, vol. 27, no. 9, pp. 11651178, 2020.

[13] X. Zhao, A. Fourie, R. Veenstra, and C. C. Qi, "Safety of barricades in cemented paste-backfilled stopes," International Journal of Minerals Metallurgy and Materials, vol. 27, no. 8, pp. 1054-1064, 2020.

[14] T. Lagos, M. Armstrong, T. Homem-de-Mello, G. Lagos, and D. Sauré, "A framework for adaptive open-pit mining planning under geological uncertainty," Optimization and Engineering, pp. 1-36, 2020.

[15] I. M. Jiskani, Q. Cai, W. Zhou et al., "Distinctive model of mine safety for sustainable mining in Pakistan," Mining Metallurgy \& Exploration, vol. 37, no. 4, pp. 1023-1037, 2020.

[16] S. Wang, W. Zhou, Q. Cai, X. Shi, X. Lu, and B. Luan, “The coal mining model under slippery slope in Yiminhe open pit coal mines," Geotechnical and Geological Engineering, vol. 37, no. 5, pp. 3727-3737, 2019. 
[17] J. Zhang, Z. Wang, and Z. Song, "Numerical study on movement of dynamic strata in combined open-pit and underground mining based on similar material simulation experiment," Arabian Journal of Geosciences, vol. 13, no. 16, 2020.

[18] L. Han, J. Shu, Q. Cai, H. Jing, and H. Tian, "Mechanical characteristics of dip basement effects on dump stability in the Shengli open pit mine in Inner Mongolia, China," Arabian Journal of Geosciences, vol. 9, no. 20, p. 750, 2016.

[19] S. Tao, H. Liu, S. Jisen, and C. Shuzhao, "Slope structure and stress development rule under mining mode of land saving and ecological detraction," Journal of China Coal Society, vol. 44, no. 12, pp. 3644-3654, 2019.

[20] L. Ma, Z. Chang, K. Li, S. Xiao, and X. Ding, "Optimization of inner dumping uncovered height with partially covered end wall in adjacent surface coal mining districts," Mathematical Problems in Engineering, vol. 2018, Article ID 5404835, 9 pages, 2018.

[21] Z. Wei, H. Liu, and C. Qingxiang, "Influence of inner dump on end-slope stability," Journal of Mining \& Safety Engineering, vol. 32, no. 4, pp. 671-676, 2015.

[22] D. Zhu, C. Lee, Q. Qian, Z. Zou, and F. Sun, “A new procedure for computing the factor of safety using the Morgenstern-Price method," Canadian Geotechnical Journal, vol. 42, no. 1, pp. 272-278, 2001.

[23] S. Y. Liu, L. T. Shao, and H. J. Li, "Slope stability analysis using the limit equilibrium method and two finite element methods," Computers and Geotechnics, vol. 63, pp. 291-298, 2015.

[24] C. Qing-xiang, Z. Wei, and S. Ji-sen, “Analysis and opplicaiton on end-slope timeliness of internal dumping under flat dipping ore body in large surface coal mine," Journal of China University of Mining \& Technology, vol. 37, no. 6, pp. 740744, 2008.

[25] Z. Zha, L. Ma, K. Li, X. Ding, and S. Xiao, "Comparative study of mining methods for reserves beneath end slope in flat surface mines with ultra-thick coal seams," International Journal of Mining Science and Technology, vol. 27, no. 6, pp. 10651071, 2017.

[26] Z. Wang, B. Liu, Y. Han, J. Wang, B. Yao, and P. Zhang, "Stability of inner dump slope and analytical solution based on circular failure: illustrated with a case study," Computers and Geotechnics, vol. 117, article 103241, 2020.

[27] T. Zhang, Q. Cai, L. Han, J. Shu, and W. Zhou, "3D stability analysis method of concave slope based on the Bishop method," International Journal of Mining Science and Technology, vol. 27, no. 2, pp. 365-370, 2017.

[28] T. Kadakci Koca and M. Y. Koca, "Comparative analyses of finite element and limit-equilibrium methods for heavily fractured rock slopes," Journal of Earth System Science, vol. 129, no. 1, p. 49, 2020. 